\title{
NUMERICAL STUDY OF THE EFFECT OF THE LOCATION OF BAFFLES ON THE FLOW AND HEAT TRANSFER OF A NEWTONIAN FLUID IN A VENTILATED ENCLOSURE
} \author{
Rachid BENNACER ${ }^{3}$ \\ ${ }^{1}$ Ecole Supérieure des Sciences Appliquées d'Alger, Algerie. \\ ${ }^{2}$ Laboratory of Transport Phenomena, USTHB, Algiers, Algeria. \\ ${ }^{3}$ LMT - ENS Cachan - CNRS - Paris Saclay University, 94230 Cachan, France
}

Abdelkader BOUTRA ${ }^{1,2}$, Seddik KHERROUBI ${ }^{2}$, Abderrahmane BOURADA ${ }^{2}$, Youb Khaled BENKAHLA ${ }^{2}$, Nabila LABSI $^{2}$,

\begin{abstract}
Flow and heat transfer analysis in ventilated cavities is one of the most widely studied problems in thermo-fluids area. Two-dimensional mixed convection in a ventilated rectangular cavity with baffles is studied numerically and the fluid considered in this study is hot air $(\operatorname{Pr}=0.71)$. The horizontal walls are maintained at a constant temperature, higher than that imposed on the vertical ones. Two very thin heatconducting baffles are inserted inside the enclosure, on its horizontal walls, to control the flow of convective fluid. The governing equations are discretized using the finite volume method and the SIMPLER algorithm to treat the coupling velocity-pressure. Line by line method is used to solve iteratively the algebraic equations. The effect of the Richardson number Ri $(0.01-100)$ and the location of the baffles within the cavity on the isothermal lines, streamlines distributions and the average Nusselt number $(\mathrm{Nu})$ has been investigated. The result shows that the location opposite the baffles, close to the fluid outlet, is the optimal choice to be considered for industrial applications.
\end{abstract}

\section{Nomenclature}

A Aspect ratio, $\mathrm{H} / \mathrm{L}$

$\mathrm{C}_{\mathrm{p}} \quad$ Specific heat capacity, $(\mathrm{J} / \mathrm{kg} \mathrm{K})$

$\mathrm{d}$ Height of the opening, (m)

g Gravity vector, $\left(\mathrm{m} / \mathrm{s}^{2}\right)$

$\mathrm{k}$ Thermal conductivity, (w/m K)

$\mathrm{k}_{\mathrm{s}} \quad$ Thermal conductivity of the baffles, $(\mathrm{w} / \mathrm{m} \mathrm{K})$

L Cavity width, (m)

$\mathrm{Nu}$ Average Nusselt number

$\mathrm{P} \quad$ Static pressure, $(\mathrm{Pa})$

$\mathrm{P} \quad$ Dimensionless pressure.

Pr Prandtl number, $=\mathrm{C}_{\mathrm{p}} \mu / \mathrm{k}$

Re Reynolds number, $=\rho \mathrm{U}_{0} \mathrm{H} / \mu$

$\mathrm{Ri}$ Richardson number

$\mathrm{T}$ Temperature, $\mathrm{K}$

$\mathrm{u}, \mathrm{v}$ Components of velocity, $(\mathrm{m} / \mathrm{s})$

U,V Dimensionless of velocity component

$\mathrm{U}_{0} \quad$ Dimensionless input speed

w Distance between baffles, (m)

$\mathrm{x}, \mathrm{y}$ Cartesian coordinates, (m)

$\mathrm{X}, \mathrm{Y}$ Dimensionless of Cartesian coordinates = $\mathrm{x} / \mathrm{H}, \mathrm{y} / \mathrm{H}$

\section{Greek letters}

$\alpha \quad$ Thermal diffusivity, $\mathrm{m}^{2} / \mathrm{s}$

$\beta \quad$ Coefficient of volume expansion, $K^{-1}$

$\rho \quad$ Density, $\left(\mathrm{kg} / \mathrm{m}^{3}\right)$ $\mu \quad$ Dynamic viscosity, $(\mathrm{kg} / \mathrm{m} \mathrm{s})$

$\theta \quad$ Dimensionless temperature, $=\left(\mathrm{T}-\mathrm{T}_{\mathrm{C}}\right) /\left(\mathrm{T}_{\mathrm{H}}-\mathrm{T}_{\mathrm{C}}\right)$.

\section{Subscript \\ $\mathrm{H} \quad \mathrm{Hot}$ \\ C cold}

\section{Introduction}

Because of its involvement in different industrial systems, such as the cooling of electrical components, thermal comfort in buildings and thermal losses in solar collectors. The ventilated cavity with obstacles is one of the configurations that has attracted the interest of researchers in recent decades; examples include the work of Rahman et al. [1-4] between 2006 and 2012, Boutra et al [5], Bilgen and Yamane [6] in 2004, and Mamun et al. [7] in 2010.

Raji et al $[8,9]$ studied flow and heat transfer within a ventilated cavity in order to justify the validity of the correlations proposed in their work. In the same context, Chan and Tien [10], Nateghi and Armfield [11], and Anil et al. [12] numerically examined the natural convection of air within ventilated cavities, in order to understand this type of phenomenon widely encountered in industry.

In light of this works, it was found that the control of the flow structure and heat transfer within this type of geometry is very recommended.

\footnotetext{
* Corresponding author: aeknad@yahoo.fr
} 
The objective of the present study is to analyse the effect of the thin baffles on the flow structure as well as on the heat transfer within a ventilated enclosure through which the hot air flows. The comparison between the forced and natural convections is performed. Therefore, the effect of Richardson number and location of the baffles on the hydrodynamic and thermal characteristics of the convective fluid is also examined.

\section{Problem statement and mathematical formulation}

The schematic of geometry and coordinate system are depicted in Figure 1, It is in fact ventilated rectangular cavity, of height $\mathrm{H}$ and length $\mathrm{L}=3 \mathrm{H}$, crossed by hot air. The ventilation is assured by two ports of the same size $(0.25 \mathrm{H})$ on the vertical walls, one at the bottom of the left wall and the other at the top of the right wall. These side walls (left and right) are maintained at a lower temperature $\mathrm{T}_{\mathrm{C}}$ than that of the horizontal walls $\mathrm{T}_{\mathrm{H}}$. Two baffles, in the form of slats of the same size, are placed vertically on the horizontal walls. They are fixed on the same wall and separated by a fixed distance, noted $\mathrm{w}$, which is equal to $0.40 \mathrm{~L}$, in certain cases, and placed on opposite walls in the other cases.

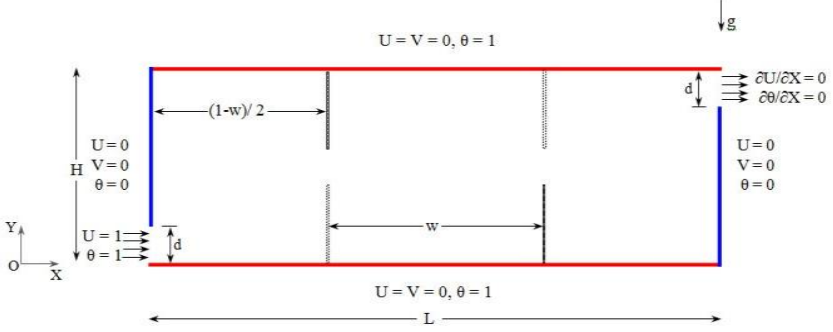

Figure.1 Simulation domain with its boundary conditions

Further, except density, the thermo-physical properties of the working fluid are assumed to be independent of the temperature and the viscous dissipation effects as well as radiation heat transfer are assumed to be neglected.

The extent of the variation of density with temperature is expressed by using Boussinesq approximation [13].

The governing equations including the twodimensional equations of the continuity, momentum, and energy for a laminar incompressible flow are presented in the following form:

$$
\frac{\partial \mathrm{U}}{\partial \mathrm{X}}+\frac{\partial \mathrm{V}}{\partial \mathrm{Y}}=0
$$

$\mathrm{U} \frac{\partial \mathrm{U}}{\partial \mathrm{X}}+\mathrm{V} \frac{\partial \mathrm{U}}{\partial \mathrm{Y}}=-\frac{\partial \mathrm{P}}{\partial \mathrm{X}}+\frac{1}{\operatorname{Re}}\left(\frac{\partial^{2} \mathrm{U}}{\partial \mathrm{X}^{2}}+\frac{\partial^{2} \mathrm{U}}{\partial \mathrm{Y}^{2}}\right)$

$\mathrm{U} \frac{\partial \mathrm{V}}{\partial \mathrm{X}}+\mathrm{V} \frac{\partial \mathrm{V}}{\partial \mathrm{Y}}=-\frac{\partial \mathrm{P}}{\partial \mathrm{Y}}+\frac{1}{\operatorname{Re}}\left(\frac{\partial^{2} \mathrm{~V}}{\partial \mathrm{X}^{2}}+\frac{\partial^{2} \mathrm{~V}}{\partial \mathrm{Y}^{2}}\right)+\mathrm{Ri} \theta$

$$
\mathrm{U} \frac{\partial \theta}{\partial \mathrm{X}}+\mathrm{V} \frac{\partial \theta}{\partial \mathrm{Y}}=\frac{1}{\operatorname{Re} \operatorname{Pr}}\left(\frac{\partial^{2} \theta}{\partial \mathrm{X}^{2}}+\frac{\partial^{2} \theta}{\partial \mathrm{Y}^{2}}\right)
$$

The averages rate of heat transfer across the side walls, are expressed in the dimensionless form by the Nusselt number:

$\mathrm{Nu}_{\text {left side }}=\int_{\mathrm{d} / \mathrm{H}}^{1}(\partial \theta / \partial \mathrm{X})_{\mathrm{X}=0} \mathrm{dY}$

$$
\mathrm{Nu}_{\text {rightside }}=\int_{\mathrm{d} / \mathrm{H}}^{1}(\partial \theta / \partial \mathrm{X})_{\mathrm{X}=1} \mathrm{dY}
$$

The dimensionless governing equations (Eqs. 1-4), together with boundary conditions, are discretized by implicit finite volume technique, which is explained by Patankar [14]. The coupling pressure-velocity is accomplished by the SIMPLER algorithm. The TriDiagonal Matrix Algorithm (TDMA) and Gauss-Seidel Algorithms are used to relax the resulting algebraic equations.

The adopted convergence criterion for our system is given by:

$$
\frac{\sum_{j=1}^{\mathrm{M}} \sum_{\mathrm{i}=1}^{\mathrm{L}}\left|\phi_{\mathrm{i}, \mathrm{j}}^{\mathrm{a}+1}-\phi_{\mathrm{i}, \mathrm{j}}^{\mathrm{a}}\right|}{\sum_{\mathrm{j}=1}^{\mathrm{M}} \sum_{\mathrm{i}=1}^{\mathrm{L}}\left|\phi_{\mathrm{i}, \mathrm{j}}^{\mathrm{a}+1}\right|} \leq 10^{-4}
$$

Where _L_ and $M_{-}$are the numbers of grid points in $X, Y_{-}$_directions, respectively._ $\phi{ }_{-}$is any of the computed field variables_(U, V, P et $\left.\theta_{-}\right)_{-}$and $\xi$ is the iteration number.

\section{Code validation}

In order to validate our homemade code (2D), written in Fortran language, we confronted our numerical results with those de Rahman et al. [4] relating to a Newtonian fluid filling a square enclosure with a heat-conducting obstacle.

Opting for an $81 \times 81$ mesh size, Table 1, representing the variation of the mean Nusselt number of the square air-filled enclosure as a function of the Richardson number, shows excellent agreement with the above results.

Note that a non-uniform $81 \times 243$ mesh will be used in our study, with a density of knots near the walls where the temperature gradient is very important. 
Table 1. Comparison of average Nusselt number for various Richardson numbers.

\begin{tabular}{c|c|c|c}
\hline & \multicolumn{2}{|c|}{ Average Nusselt number } & \\
\hline Ri & Rahman et al. $_{\text {. }}$ [] & Present work & Gap (\%) \\
\hline 0 & 4.136 & 4.105 & 0.75 \\
\hline 1 & 4.847 & 4.888 & 0.84 \\
\hline 3 & 5.290 & 5.282 & 0.03 \\
\hline 5 & 5.732 & 5.699 & 0.75 \\
\hline
\end{tabular}

\section{RESULTS \& DISCUSSION}

\section{Case of mixed convection}

First, let's start by studying the case of mixed convection. $(\mathrm{Ri}=1)$ and the hydrodynamic and thermal behaviour of the warm air within the partitioned enclosure.

Figure 2 illustrates the different flow structures and isotherms for different baffle positions within the enclosure.

In the first case, (Figure 2(a) the presence- near the vertical walls- of two contra-rotating recirculation zones is observed. The rotating cell near the left wall is more important and rotates counter-clockwise. In the centre of the cavity, we note the presence of three zones: one located downstream of the lower baffle plate, turning clockwise, and two upstream and downstream of the upper baffle plate, turning counter-clockwise.

In the second case- (figure 2(b)) the two counterrotating recirculation zones occupy almost all the space delimited by the vertical walls and the baffles, with the presence of a zone in the middle that rotates clockwise.

In the case where the two baffles are placed on the lower wall. Figure 2(c). in addition to the two counterrotating cells, there is also a cell downstream of the baffle near the left wall- which rotates clockwise, in contrast to the case of two baffles placed on the upper wall. Figure 2(d). Where the recirculation area rotates counterclockwise.

When the two baffles are placed opposite each other, figure 2(e), two counter-rotating cells downstream of the baffles are observed. At the inlet, the flow diverges and then converges as it passes through the melt created by the baffles.

Near the right wall, in the last case, a counter-clockwise recirculation zone is located downstream of the baffle grafted on the upper wall, while the cell near the left vertical wall, occupies the upper half of the cavity.

Finally, it should be noted that the isotherms in the vicinity of the cold vertical walls are tightening, reflecting an intensification of exchanges at this level.

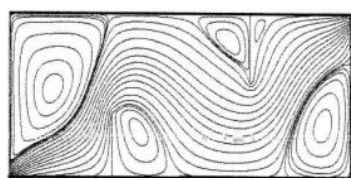

Case

(a)
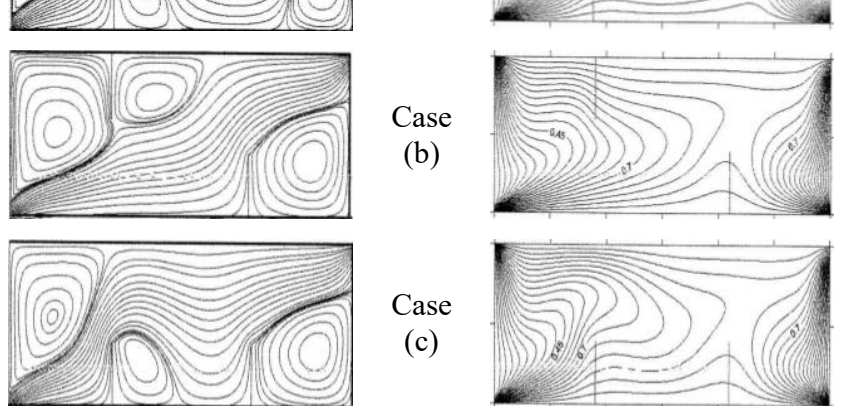

Case

(c)
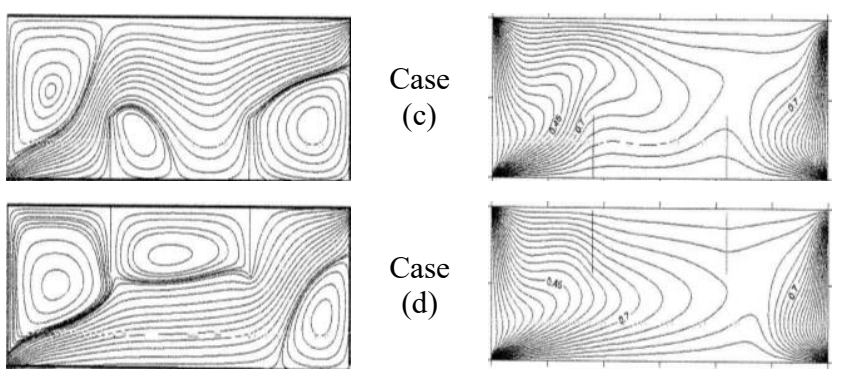

Case
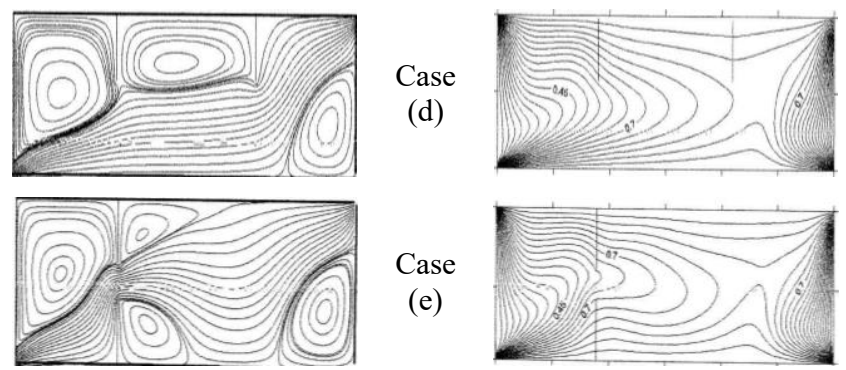

Case

(e)
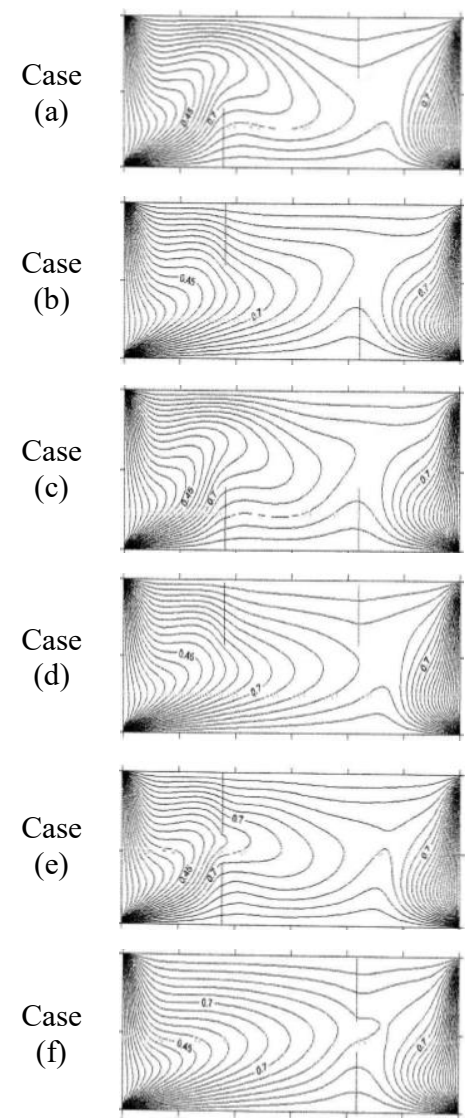

(a)

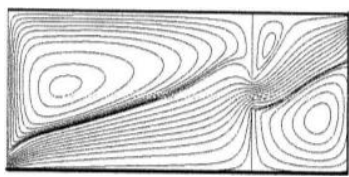

(b)

Figure (2): Streamlines (a) and Isotherms(b) depending on the position of the baffles for $\mathrm{Ri}=1$ and $\mathrm{Pr}=0.7$

\section{Case of forced convection}

When forced convection dominates, Figure 3, the zones of recirculation, observed previously, weakened as a result of the increase in the velocity of the convective fluid. The recirculation zone above the cavity inlet remains and takes on different sizes due to the position of the baffles, while the recirculation zone below the fluid outlet takes only place when the bottom baffle is close to the right wall. As a result, a convective regime is observed in the enclosure, while conduction dominates near the right wall (see Isotherms).
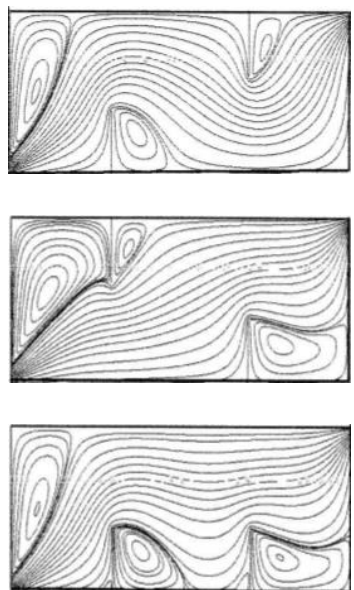

Case

(a)

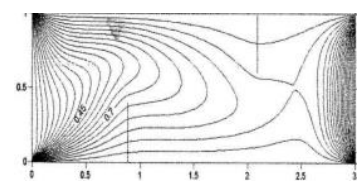

Case

(b)

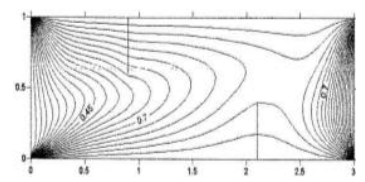

Case

(c)

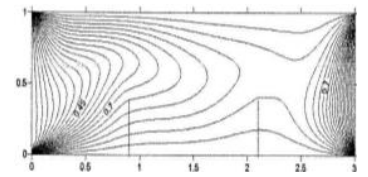




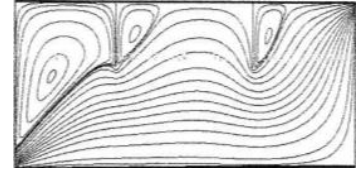

Case

(d)
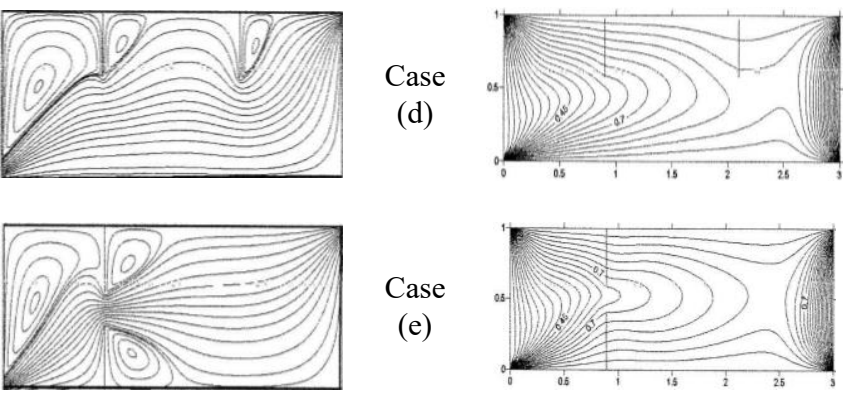

Case

(e)
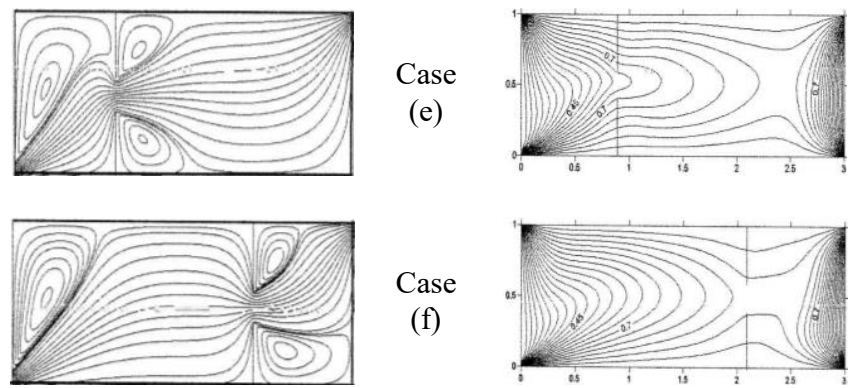

Case

(f)

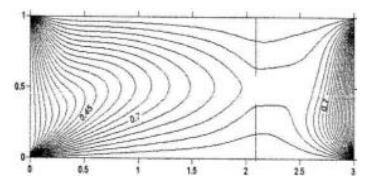

Figure (3): Streamlines (a) and Isotherms (b) depending on the position of the baffles for $\mathrm{Ri}=0.01_{-}$and $\mathrm{Pr}=0.7$

\section{Case of natural convection}

When the Richardson number is taken equal to 100 , indicating a natural convection mode, the main flow of the convective fluid disappears completely.

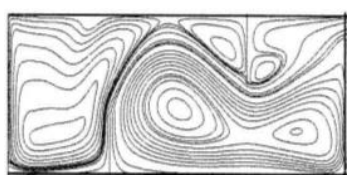

Case

(a)
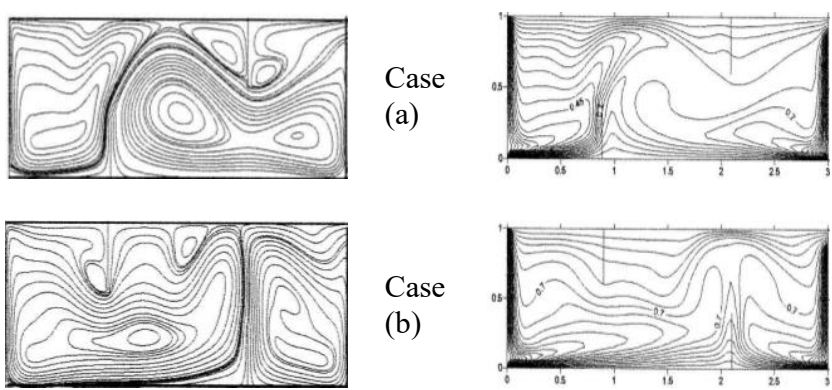

Case

(b)
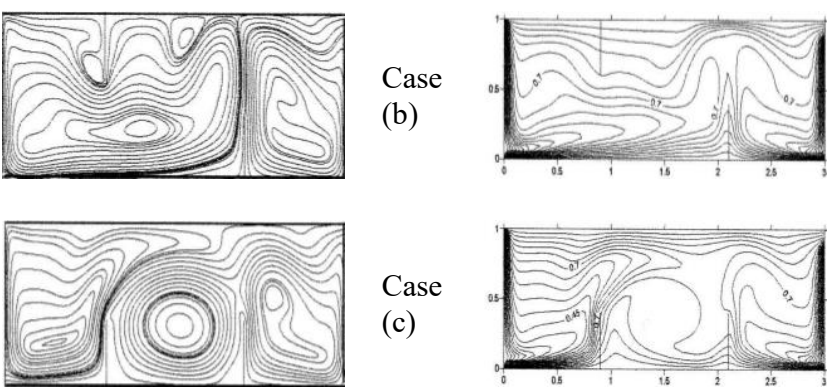

Case
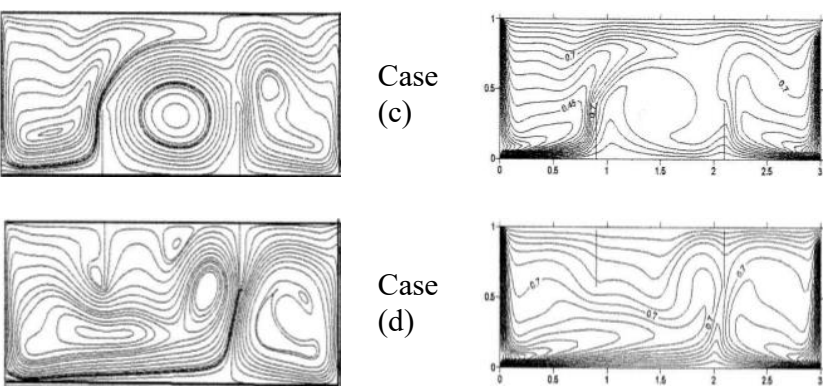

Case

(d)
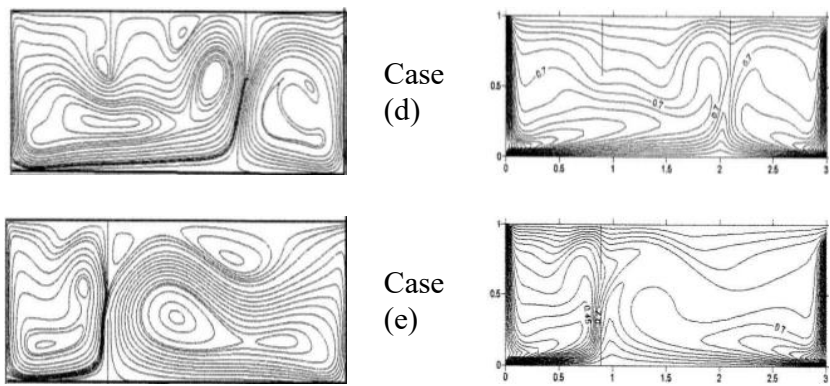

Case

(e)
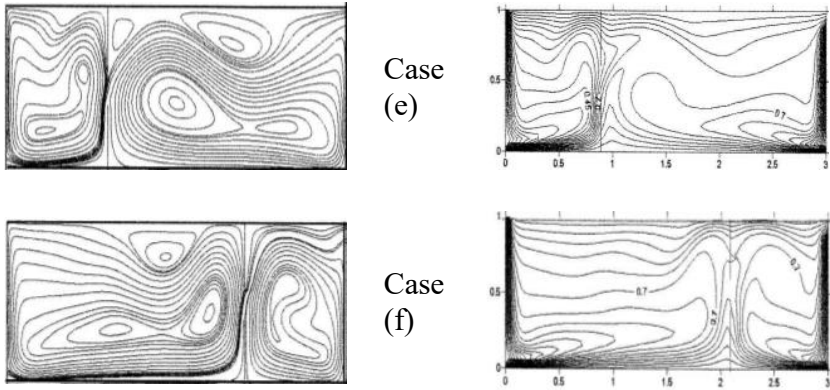

Case

(f)

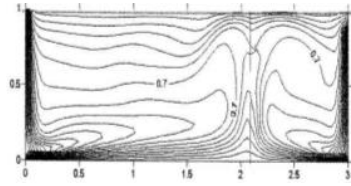

Figure (4): Streamlines (a) and Isotherms (b) depending on the position of the baffles for $\mathrm{Ri}=100$ and $\mathrm{Pr}=0.7$

Thermal boundary layers are formed in the vicinity of the cold vertical walls and along the bottom wall, thus reflecting strong gradients in these areas and consequently better heat transfer.

\section{Heat transfer rate}

Table 2 shows the evolution of the average Nusselt number, calculated along the cavity, with various values of Richardson number for the different baffle arrangements.

The rate of heat transfer evolves as an increasing function with the Richardson number as a result of previously observed convective fluid behaviour, while the best transfer is calculated using the latest baffle arrangement.

Table 2 : Average Nusselt number

\begin{tabular}{cccc}
\hline \multicolumn{4}{c}{ Average Nusselt number } \\
\hline Case & $\mathrm{Ri}=0.01$ & $\mathrm{Ri}=1$ & $\mathrm{Ri}=100$ \\
\hline 01 & 7.71 & 8.18 & 13.73 \\
02 & 7.76 & 8.36 & 14.08 \\
03 & 7.73 & 8.31 & 13.65 \\
04 & 7.74 & 8.22 & 14.10 \\
05 & 7.67 & 8.19 & 13.36 \\
06 & $\mathbf{7 . 9 1}$ & $\mathbf{8 . 4 7}$ & $\mathbf{1 4 . 2 1}$ \\
\hline
\end{tabular}

\section{Conclusion}

The study of the hydrodynamic and thermal behaviour of a Newtonian fluid within a ventilated rectangular cavity, equipped with two baffles, in the form of a lamella, of the same dimension was carried out numerically, using a calculation code based on the finite volume method. The effect of the number of Richardson and the location of the baffles was examined. In this study we found that the rate of heat transfer is found to be an increasing function of Richardson's number. The results of the comparison between the cases studied lead to conclude that the location opposite the baffles, close to the outlet of the convective fluid, is the best choice to be considered for industrial applications.

\section{Keywords}

Mixed convection, Numerical study, baffles, ventilated enclosure

\section{References}

[1] M.M. Rahman, M. Alim, S. Saha, M. Chowdhury. Nonlinear Analysis: Model. Control. 14 (2009).

[2] M.M. Rahman, S. Parvin, N. Rahim, M. Islam, R. Saidur, M. Hasanizzaman. Appl. Math. Model, 36 (2012). 
[3] M.M. Rahman, M. Alim, S. Sah, x M.K. Sah. A Journal of Mechanical Engineering, 42, 2 (2006).

[4] M.M. Rahman, M. Elias, M. Alim. Asian Res. Pub. Network 75 (2006).

[5] A. Boutra, K. Ragui, Y.K. Benkahla, N. Labsi, Theoretical Foundations of Chemical Engineering, 52, 2(2018).

[6] E. Bilgen, T. Yamane., Heat Mass Transf. 40 (2004).

[7] M.A.H. Mamum, M.M. Rahman, M.M. Billah, R. Saidur. Int. Commun. Heat Mass Transf., 37 (2010).

[8] A. Raji, M. Hasnaoui., Rev. Gen. Therm. 37 (1998).

[9] A. Raji, M. Hasnaoui, A. Bahlaoui. Int. J. Heat Fluid Flow, 29 (2008).

[10] Y.L. Chan, C.L. Tien. Int. J. Heat Mass Transf. 28 (1985).

[11] M. Nateghi, S.W. Armfield. J. ANZIAM, 45 (2004).

[12] L. Anil, C. Reji. Int. J. Heat Mass Transf. 52 (2009).

[13] A. Bejan., John Wiley and Sons, Inc., Hoboken, New jersey, USA, (2004).

[14] S.V. Patankar, Hemisphere Publishing Corporating, Taylor and Francis Group, New York, (1980). 